\title{
Bryan total disc arthroplasty: a replacement disc for cervical disc disease
}

This article was published in the following Dove Press journal:

Medical Devices: Evidence and Research

29 July 2010

Number of times this article has been viewed

\author{
Markus Wenger ${ }^{\prime}$ \\ Thomas-Marc Markwalder ${ }^{2}$ \\ 'Neurosurgery, Klinik Beau-Site and \\ Salem-Spital, Berne, Switzerland; \\ ${ }^{2}$ Attending Neurosurgeon FMH, \\ Private Practice Spine Surgery, \\ Berne-Muri, Switzerland
}

\begin{abstract}
Total disc arthroplasty is a new option in the treatment of cervical degenerative disc disease. Several types of cervical disc prostheses currently challenge the gold-standard discectomy and fusion procedures. This review describes the Bryan Cervical Disc System and presents the Bryan prosthesis, its indications, surgical technique, complications, and outcomes, as given in the literature.
\end{abstract}

Keywords: cervical spine, degenerative disc disease, disc herniation, myelopathy, spine surgery, bryan prosthesis, complication, outcome

\section{Introduction}

Degeneration of an intervertebral disc involves progressive dehydration and fibrosis of the nucleus pulposus. These modifications induce loss of elasticity, loss of intervertebral height, formation of osseous spurs, cracking and bulging of the annulus fibrosus, and eventually, extrusion of nucleus tissue. ${ }^{1}$ Advanced degenerative disc disease destabilizes the anterior spinal column. Each of these events may generate pain. Nuchalgia, restriction of head movements, muscular spasms, torticollis, headaches, and pseudoradicular complaints are frequently reported. In the case of nucleus pulposus herniation into the spinal canal or the foraminal area, neural elements are usually compressed. Radicular pain in the supply area of the respective nerve is characteristic of nerve root compression. Nerve root compression may also be associated with neurological deficits such as sensible dysfunction, abolished tendon reflex, and paresis. Compression of the spinal cord results in myelopathy. Common clinical findings of myelopathy are hyperreflexia, clonus, disabling disturbances of gait, equilibrium, coordination, and difficulty handling small objects. ${ }^{2-5}$

Recent disc herniations often heal spontaneously or favorably respond to conservative treatments. In case of severe symptoms, microdiscectomy combined with segment fusion is required. However, this otherwise successful procedure is associated with a significant incidence of accelerated adjacent-segment degeneration. ${ }^{2,6,7}$ Ultimately, adjacent-segment morbidity requires further interventions. Maintaining motion at the index segment is believed to be an important approach to reducing problems at transient segments. $4,6,8-12$

Based on this knowledge, Dr Vincent Bryan developed his total cervical disc arthroplasty device in the 1990s. Dr Goffin of Belgium implanted this prosthesis for the first time in January $2000 ., 8,13,14$ The aim of this review is to present the Bryan ${ }^{\circledR}$ Cervical Disc System (Medtronic Sofamor Danek; Memphis, Tennesse) and its use in
Correspondence: Markus Wenger Oberarzt Klinik Beau-Site, Schänzlihalde II, CH-3000 Berne 25, Switzerland Tel +4I(0) 3I 3353333 Fax $+4 I(0) 3 I 95 I 5058$ Email aerzte.beau-site@hirslanden.ch 
the treatment of degenerative disc disease. Several types of cervical disc prostheses are marketed at present. ${ }^{1,13,15}$

\section{Surgical gold standard}

The standard surgical procedure for cervical degenerative disc disease or disc herniation has been in use for more than 50 years. It involves an anterior approach to the cervical spine and removal of the disc with the offending tissue (anterior cervical discectomy $[\mathrm{ACD}]) .{ }^{16,17}$ This procedure is safe in view of nerve decompression. ${ }^{15,18}$ However, ACD alone shows a tendency to create subsequent problems. The most notable are pain because of chronic instability or malalignment of the operated segment, as well as adjacent-segment disease.

In order to improve reliable bony fusion in correct alignment, surgeons began inserting a corticocancellous bone graft into the disc space (ACD with fusion [ACDF] $){ }^{1,2,16,19,20}$ Later, these bone grafts were replaced by custom-made interbody fusion cages, ${ }^{21}$ which reduce the problem of matching the shape of the graft to the disc space and annoying transformations of the bone graft during the healing process. Because cages require only a small amount of autologous cancellous bone or a bone substitute, the severity of graft harvest site problems is significantly reduced. A plate-screw osteosynthesis is added if the stability of the cage construct is considered to be insufficient. Introduction of the operating microscope (microdiscectomy) allowed for magnification and direct illumination of the surgical field, rendering operations more precise and safe. These technical adaptations significantly improved ACD outcome; however, the problem of transitional-segment disease with subsequent interventions remained unsolved.

Nevertheless, at present, microdiscectomy with cage insertion and eventual plating represents the gold standard in the surgical treatment of cervical degenerative disc disease and disc herniation. ${ }^{5,18,22} \mathrm{ACDF}$ is associated with favorable long-term results. ${ }^{1,4,8,15,18,22-24}$

Table 1 compares the ACDF and the Bryan procedures.

\section{Rationale for cervical total disc arthroplasty}

There are three main reasons why researchers look for improvements to the successful gold-standard ACDF procedure.

First, most surgeons believe that creation of an osseous block out of a functional motion segment has long-term adverse effects on adjacent segments below ${ }^{6,10}$ and, more frequently, above $\mathrm{e}^{14,25}$ the block. Adjacent levels are subject to increased strain, motion, and intradiscal pressure (mechanical overcharge), as they have to take over the work of the fused segment. ${ }^{2,5-7,9,13,18,24,26}$ Consequently, they tend to degenerate early. ${ }^{2}$ Elongation of the spondylodesis, including this pain-generating segment, is required later in many patients. ${ }^{14,15}$ Hilibrand et $\mathrm{al}^{2}$ reported an annual mean rate of $2.9 \%$ adjacent-segment disease during the first 10 years after operation; however, this value did not consider the inherent course of degeneration. Their Kaplan-Meier survivorship analysis of 374 fused patients revealed an incidence of $25.6 \%$ at 10 years. The risk of adjacent-segment disease was lowest for fusions at $\mathrm{C} 2 / 3$ and $\mathrm{C} 6 / \mathrm{T} 1$, intermediate at $\mathrm{C} 3 / 4$ and $\mathrm{C} 4 / 5$ (factor 3.2), and highest at $\mathrm{C} 5 / 6$ and $\mathrm{C} 6 / 7$ (factor 4.9). ${ }^{2}$ In the long run, more than two-thirds of their patients who developed new transitional-segment disease needed further operations. They considered the inherent process of degeneration to be a more probable cause of adjacent-segment disease than increased stress after spondylodesis. ${ }^{2}$ Robertson et $a{ }^{10}$ found new symptomatic adjacent-disc disease after 158 fusions in 13.9\% (6.9\% annually) of patients at 2 years and considered transitional-level disease to be a sequela of spondylodesis. Goffin et $\mathrm{al}^{27}$ also reported a $92 \%$ incidence of radiologic adjacent-segment degeneration after ACDF (mean follow-up of 100.6 months, $>60$ months for all; mostly degenerative and trauma cases). However, only $6.11 \%$ (11 of 180) of patients eventually required surgery. Garrido et al ${ }^{24}$ analyzed three ACDF patients (12\%) who underwent revision surgery for adjacent-segment disease within 48 months: one for remote-level degeneration and two for pseudoarthrosis formation, whereas only one $(5 \%)$ had revision surgery in the Bryan cohort. There was a clear trend toward fewer secondary interventions in the Bryan group. Wigfield et $\mathrm{al}^{6}$ reported that fusion increased motion at adjacent levels.

Second, reoperations of the original segment, even though rare, ${ }^{27}$ are required to treat pseudoarthrosis formation, graft migration, or graft collapse (eg, graft nonunion rate of $6 \%$ at 2 years in 221 single-level ACDF patients ${ }^{18}$ ). ${ }^{1,9,15,18,24,27}$ In the case of plate-screw osteosynthesis, implants fail, may become loose, and even migrate, ${ }^{1,28}$ and the implants have to be removed.

Third, problems occurring at the graft harvest site (usually anterior iliac crest) such as hematoma formation, infections, chronic pain, meralgia paresthetica, lesions of the sacroiliac joint, and even pelvic fractures blur the otherwise favorable results. ${ }^{1,15,29,30}$ Sandhu et al ${ }^{29}$ reported a graft harvest site complication rate of up to $25 \%$. 
Table I Comparison between the gold-standard ACDF procedure and Bryan total disc arthroplasty in the treatment of cervical degenerative disc disease and eventual disc herniation

\begin{tabular}{|c|c|c|}
\hline & ACDF & Bryan total disc arthroplasty \\
\hline Indication & $\begin{array}{l}\text { Degenerative disc disease, } \pm \text { disc herniation, } \pm \text { arthrosis } \\
\text { formation, instability, too low or high disc space }\end{array}$ & $\begin{array}{l}\text { Degenerative disc disease, } \pm \text { disc herniation, } \pm \text { only mild } \\
\text { myelopathy, otherwise healthy individual and cervical spine } \\
\text { (see text); up to } 43 \%{ }^{15} \text { of patients }\end{array}$ \\
\hline Segments to be treated & $\mathrm{C} 2 / 3$ to $\mathrm{C} 7 / \mathrm{TI}$ & $\begin{array}{l}\text { Approved for } \mathrm{C} 3 / 4 \text { to } \mathrm{C} 6 / 7 ; 25 \text { also used rarely at the } \\
\text { cervicothoracal junction }{ }^{10,15,28}\end{array}$ \\
\hline No. of segments & I to several & $1-2$ (or 3). \\
\hline Fluoroscopy & $\begin{array}{l}\text { Localization of the target space, and final control of the } \\
\text { cage's position and alignment }\end{array}$ & $\begin{array}{l}\text { Permanent use for patient adjustment, assessment of axis, } \\
\text { burring, milling, and final control; increased exposure for } \\
\text { patient and personnel }\end{array}$ \\
\hline Instruments & Microdiscectomy instruments & $\begin{array}{l}\text { Microdiscectomy instruments }+ \text { Bryan frame }+ \text { Bryan } \\
\text { instruments }\end{array}$ \\
\hline Access & $\begin{array}{l}\text { Standard anterior with oblique, curvilinear, or horizontal } \\
\text { incision }^{16,17,19,20}\end{array}$ & $\begin{array}{l}\text { Standard anterior with oblique, curvilinear, or horizontal } \\
\text { incision; exposure slightly larger to allow access for milling } \\
\text { fixture }\end{array}$ \\
\hline Microscope & Yes & Yes \\
\hline Duration of surgery & $\begin{array}{l}\text { Short; graft harvest prolongs operating time; in case of } \\
\text { osteosynthesis, probably identical with Bryan }\end{array}$ & $\begin{array}{l}\text { Slightly longer }{ }^{5,24} \text { (some exceptions }{ }^{3} \text { ); time for mounting of } \\
\text { the scaffolding and adjusting slightly exceeds time for ACDF } \\
\text { with graft harvest; learning curve }\end{array}$ \\
\hline Implant & $\begin{array}{l}\text { Cage (usually carbon, PEEK or metallic), eventual plate- } \\
\text { screw osteosynthesis (titanium, steel) }\end{array}$ & $\begin{array}{l}\text { One-piece, bi-articulating, axially and functionally symmetric } \\
\text { prosthesis (titanium alloy, polyurethane, saline) }\end{array}$ \\
\hline Autologous bone graft & $\begin{array}{l}\text { Yes; possible graft site complications; alternatively bone } \\
\text { substitutes }\end{array}$ & None \\
\hline Plate-screw osteosynthesis & Sometimes & None \\
\hline Blood loss & Negligible $^{24}$ & $\begin{array}{l}\text { Negligible; slightly higher due to burring and milling of bony } \\
\text { surfaces } 5,9,11,24\end{array}$ \\
\hline Possible complications & Bleeding, N. laryngeus, dysphagia, infection; graft harvest site & Bleeding, N. laryngeus, dysphagia, infection; device related \\
\hline Post-operative measures & $\begin{array}{l}\text { We use rigid collars that restrict head movements, }{ }^{2} \\
\text { even though others avoid stiff collars }\end{array}$ & No collar; no restriction of head movements ${ }^{14}\left(\right.$ exception $\left.^{24}\right)$ \\
\hline Costs of surgery & $\begin{array}{l}\text { Relatively low (surgery, cage, eventual bone substitute, } \\
\text { rigid collar) }\end{array}$ & Relatively high (surgery, prosthesis) ${ }^{33}$ \\
\hline Back to work & Later & Earlier $5,18,23$ \\
\hline Overall costs & Probably more & Probably less \\
\hline $\begin{array}{l}\text { Adjacent segment after } \\
\text { surgery }\end{array}$ & $\begin{array}{l}\text { Potential of mechanical overload over the long term } \\
\text { (overload adds to inherent degeneration) }\end{array}$ & Assumed protection over the long term \\
\hline Published follow-up & Long term (first operation $>50$ years ago) ${ }^{16,19,20}$ & $\begin{array}{l}\text { Short to intermediate term, }<5 \text { years (first Bryan } \\
\text { implantation in } 2000^{5,13} \text { ) }\end{array}$ \\
\hline
\end{tabular}

Abrreviation: ACDF, anterior cervical discectomy with fusion; N, nervuus; PEEK, polyether ether ketone.

\section{Assessment of patients with cervical degenerative disc disease}

In many instances, the history and clinical presentation of a patient with degenerative disc disease and cervical disc herniation are specific. ${ }^{22}$ At this point, the radiological assessment is initiated, and we prefer magnetic resonance imaging (MRI) of the cervical spine to be the first investigation. ${ }^{15}$ MRI depicts huge osseous spurs, neural structures, the condition of the disc, disc herniations, and the relation between a sequester and the nerves. In T2-weighted MRI, degenerated discs have a dark, dehydrated appearance (black disc), and sometimes they appear collapsed. Abnormalities in the area of the endplate and the adjacent bone marrow reflect painful mechanical overload (eg, vertebral edema formation, Modic sign). ${ }^{31}$ In severe myelopathy, MRI reveals signal alterations within the spinal cord. The central canal is studied. However, function of the motion segment cannot be assessed by conventional MRI. This is why X-rays in anteroposterior and lateral directions, as well as a functional series of conventional radiographs with full flexion and extension of the head, are mandatory (caveat: severe myelopathy). These images reliably show hypermobility or hypomobility of the segment, height of the disc space, and significant changes due to arthrosis formation. In a few ambiguous cases, usually a more detailed examination of the relation between discrete osseous changes and neural elements is needed. In these instances and in cases of MRI contraindications, functional myelography and myelography combined with computed 
tomography (CT) are also used. ${ }^{15}$ We use nerve conduction or electromyography studies only to exclude nervus medianus or ulnaris compression syndromes. ${ }^{4}$

\section{Indication and contraindication for Bryan disc implantation}

In cervical degenerative disc disease, a conservative treatment is initiated. ${ }^{1}$ Therapy involves analgesics, muscle relaxants, anti-inflammatory medications, immobilization in a rigid orthosis, and physical therapy. Nonresponders are evaluated for total disc arthroplasty within a reasonable period of time (eg, 3 months in the Swiss protocol; others after 6 weeks $^{9,18,24,32}$ or 6 months ${ }^{15}$ ).

Arthroplasty, usually an elective surgery, requires good general health and is possible only in adults (mature skeleton; 21 years $^{25}$ to $<60$ years of age, ${ }^{1,33}$ rarely $>60$ years $^{10,15}$ ). There should be no local or systemic infection (including HIV and hepatitis B and C), ${ }^{15}$ allergy to any component of the implant, medical therapy interfering with bone healing (eg, steroids), diabetes mellitus, chronic kidney disease, severe obesity (body mass index $>40 \mathrm{~kg} / \mathrm{m}^{215}$ ), active malignancy, pregnancy, or a general disorder of the skeleton, such as rheumatoid arthritis, osteopenia, or osteoporosis. ${ }^{1,4,5,11,12,15,18,25,33}$ Short necks and superimposed, large shoulder girdles obviate fluoroscopy of caudal segments. ${ }^{8,18,28}$ Axial neck pain alone should not be treated by arthroplasty. ${ }^{3,15}$

Minor spondylosis with anterior, posterior, and uncovertebral spurs is frequently encountered. These osteophytes can easily be removed during surgery. ${ }^{15}$ However, individuals presenting with facet arthrosis, target disc space height less than $50 \%$ of the normal, ${ }^{5,15,18}$ kyphotic target segments, ${ }^{12,34,35}$ olisthesis of $\geq 2,{ }^{5,25,32} 3,4,15$ or $3.5 \mathrm{~mm},{ }^{9,24}$ instability with angular motion of $\geq 11^{\circ}$ more than either adjacent segment, ${ }^{5,15,24,28,32}$ and spontaneous fusion (ie, $<2^{\circ}$ motion) $)^{5,15}$ should not undergo arthroplasty., $, 5,15$

We consider myelopathy to be an absolute contraindication. ${ }^{25}$ Without analysis, we believe that the chance of healing will be greater if the diseased part of the spinal cord is immobilized as much as possible by creating an osseous block. The importance of healing myelopathy, or at least stopping its progression, outweighs all the advantages of arthroplasty. Nevertheless, many surgeons treat patients with myelopathy. $3,5,11,15,18,23-25,28,32,33,36,37$ The probably treat myelopathy due to strict retrodiscal offending tissue ${ }^{9}$ and exclude patients with myelopathy due to posterior or retrovertebral compression (eg, ossification of the posterior longitudinal ligament $\left.[\mathrm{OPLL}]^{8}\right)$.
In our view, previous cervical spine surgery, at least at the target segment, ${ }^{15}$ as well as previous cervical trauma (eg, whiplash injury), is a criterion for exclusion. ${ }^{1}$ Nevertheless, some surgeons implant prostheses after neck surgery, ${ }^{28,37}$ and others even combine arthroplasty and fusion. ${ }^{11}$

Because the rate of complications increases per treated level, we never implant more than two prostheses. ${ }^{25,28,38}$ Some surgeons restrict arthroplasty to a single-level disease, ${ }^{1,12,18}$ some treat up to three levels, ${ }^{28,37}$ and some surgeons only advise against the treatment of more than three levels. ${ }^{15}$

Auerbach et $a 1^{15}$ showed that $43 \%$ of patients with cervical degenerative disc disease are possible arthroplasty candidates (conversely, 57\% have contraindications); however, only $8.4 \%$ (14 of 167) had nonfusion surgery. Costs, national healthcare politics, and other nonmedical factors obviously have an impact on patient selection.

Individuals with new paresis or myelopathy need either arthroplasty or ACDF on an emergency basis.

\section{Bryan prosthesis}

The Bryan prosthesis is composed of two convex titanium alloy spheres, an intervening polyurethane core that articulates with each sphere, a polyurethane circular wall, and a cavity (Figures 1-4). 1,3,8,13,14,25,39 It is axially and functionally symmetric (ie, no lordotic shape). ${ }^{1,12,36}$ The prosthesis comes in a one-piece, preassembled device. Once saline is injected into the cavity, the device is ready for implantation. Currently, the prosthesis is available with diameters

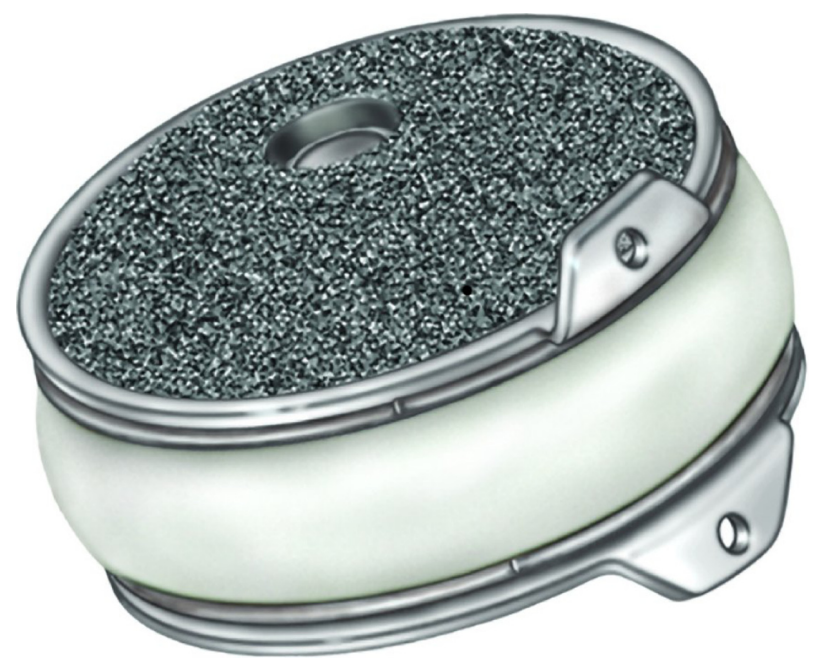

Figure I Bryan cervical disc prosthesis. There are two porous convex shells with the central access port to the void and two punched anterior stops, as well as the polyurethane sheath retained by two wires. Reproduced with permission from Medtronic Sofamor Danek USA, Inc. 


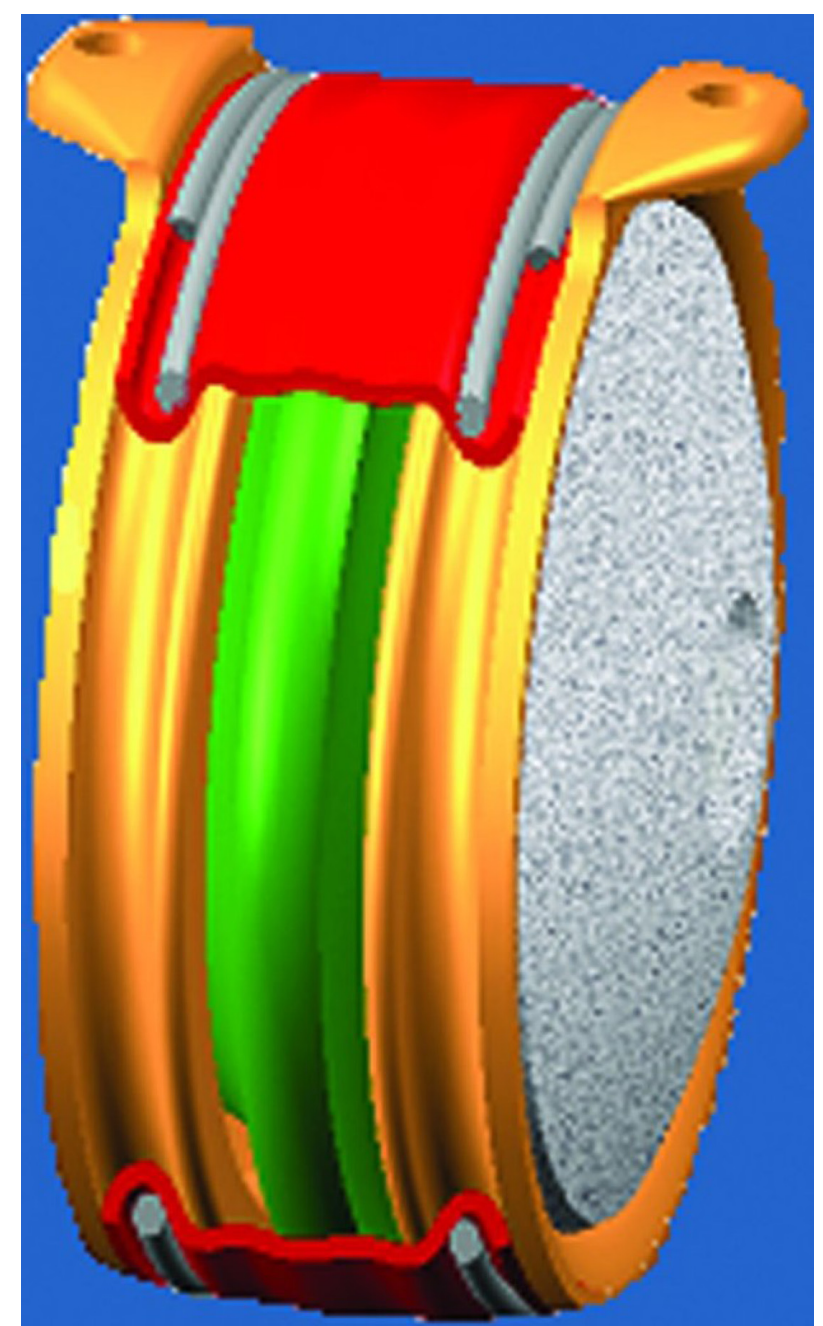

Figure 2 Partial removal of the retiring wires and the sheath (red) opens the space of the lubricant (not shown) and uncovers the nucleus (green) bi-articulating with the shells (yellow). Reproduced with permission from Medtronic Sofamor Danek USA, Inc.

of $14-18 \mathrm{~mm}$ and a height of $8.5 \mathrm{~mm} .^{3,25,36}$ The device is approved for implantation at $\mathrm{C} 3 / 4$ to $\mathrm{C} 6 / 7 .{ }^{25} \mathrm{It}$ is rarely used at the cervicothoracic junction as well. ${ }^{10,15,28,37}$

The shells consist of a titanium-aluminium-vanadium alloy, and their outer surfaces are convex. High-friction porosity is obtained by the fusion of $250-\mu \mathrm{m}$ titanium pellets onto their surfaces. ${ }^{5}$ The concave inner surfaces, articulating with the core, are polished to prevent wear debris formation. Each endplate has a metallic center post. The posts fit into the center dents of the nucleus. There is a low circular rim all along the periphery of the spheres, which is directed toward the vertebral endplates. At identical locations of the outer edge, each shell has a perpendicular, punched flange (anterior stop) bent cephalad on the upper shell and caudal on the lower endplate.

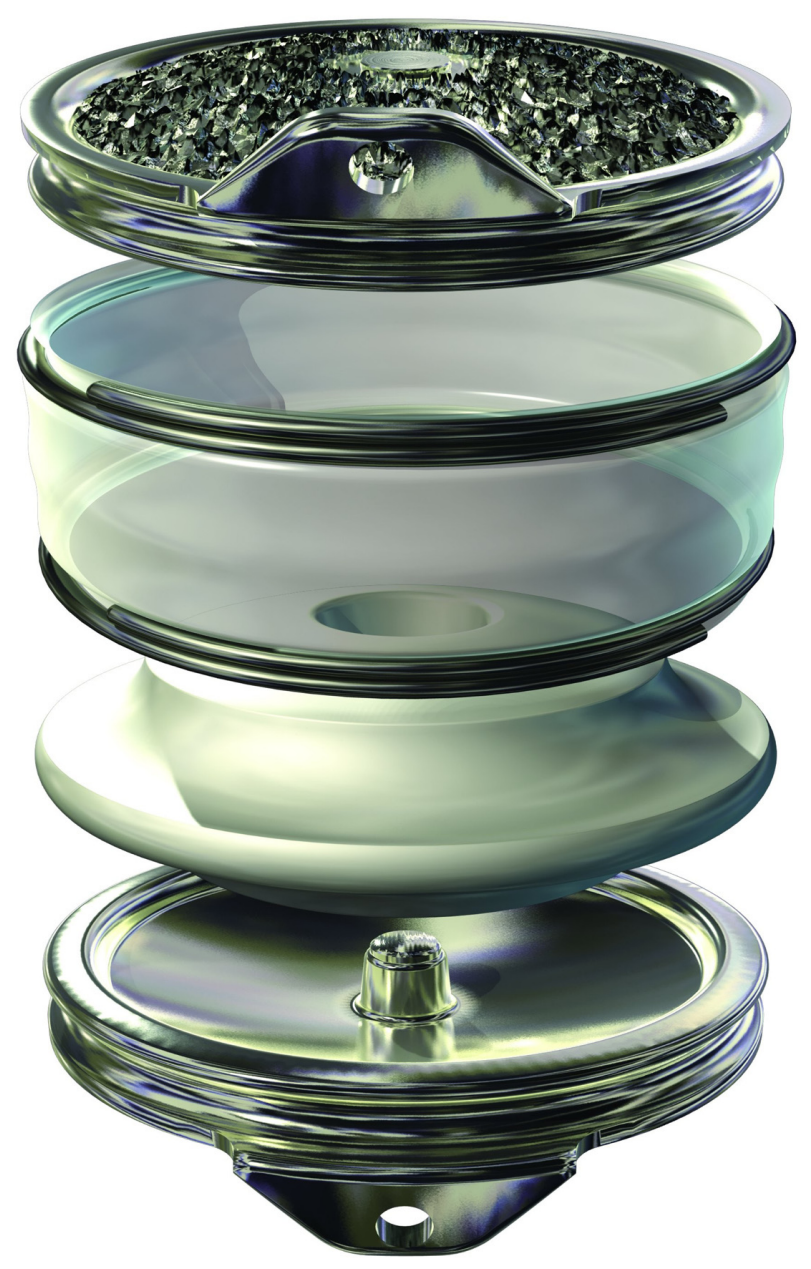

Figure 3 In this "explosion" picture, each component of the prosthesis is vertically displaced. Note the polished convex inner surface of the shell, which articulates with the nucleus, and the groove of the shell that accommodates the wire. The central dent of the nucleus is visible through the sheath, which appears transparent in this drawing. Reproduced with permission from Medtronic Sofamor Danek USA, Inc.

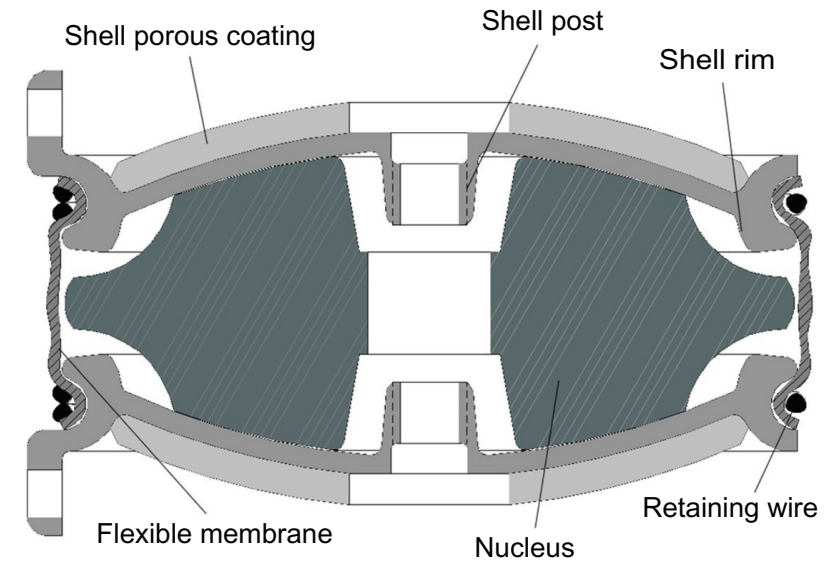

Figure $\mathbf{4}$ Cross section of Bryan prosthesis. The void is located around the center post, squeezed between endplates and the nucleus, and visible again in the area of the sheath (membrane) and the shell rim. Note that the nucleus is convex at the center and concave at the outer border. Reproduced with permission from Medtronic Sofamor Danek USA, Inc. 
Most of the device is filled with a low-friction core of medical-grade polyurethane. The surface geometry of the nucleus is convex, and it matches with the titanium alloy endplates. However, in the area of the shell rims, the nucleus changes its shape and becomes biconcave.

A circular polyurethane band connects the two spheres. It is retained by a wire in the groove at the outermost margin of each shell. The sheath represents the vertical wall of the device.

There is a single void in the center of the device. It is confined by the spheres, the core, and the sheath. In the center of each sphere, there is a port with access to this cavity.

Each part of the prosthesis has a specific function. The convex endplates, with their rims, exactly fit to the precisionmilled vertebral recesses. This feature provides for immediate or primary stability after the release of disc space distraction. Prior to bone ingrowth, the shell's rough texture protects against excessive torsion. Maximal capping of the vertebral endplates shares the loads applied to the device and impedes osseous bridging of the device. ${ }^{28,38}$ Porosity allows for bony ingrowth, ${ }^{14}$ which represents late or secondary stability. Even though they are not reliable in all instances, ${ }^{28}$ anterior stops anticipate posterior dislocation during surgery and later in life. Intraoperatively, the introducer instrument is attached to the punches in the stops. The flanges may be useful during revision surgery. ${ }^{33}$

The high-resistance polyurethane core absorbs axial, torsional, and shear loads. It allows for torsion, a maximum of $11^{\circ}$ flexion, extension, lateral bending, $2 \mathrm{~mm}$ of translation, and any combination of these. , $^{814,36,39}$ Motion is stopped if the shell's center post comes in contact with the wall of the dent. Contact between the outermost border of the shell and the peripheral concavity of the nucleus limits motion as well. However, motion is stopped by the prosthesis only if surrounding anatomical structures such as facet articulations, ligaments, and remnants of the annulus fail to stop motion before. In this way, the prosthesis is unconstrained for physiological motion. ${ }^{12,39}$

This semipermeable polyurethane sheath retains polymeric wear debris ${ }^{1}$ and prevents soft tissue ingrowth. ${ }^{39}$ Later, a pseudocapsule of noninflammatory fibrovascular tissue may arise around the sheath. ${ }^{9,8}$

Permanently submerged into sterile physiological saline (initial lubricant) the device is prepared intraoperatively. One seal plug is screwed into the sphere, and the device is turned onto this sphere, repetitively squeezed in order to eliminate as many air bubbles as possible, and slightly compressed (see kyphosis formation discussed later). In this state, the second seal plug is closed. Usually, the height of the prepared prosthesis is less than $8.5 \mathrm{~mm}$, and the shells are no longer parallel. After implantation and release of distraction, the spheres adjust themselves to the vertebral endplates.

Titanium, titanium alloy, and polyurethane implants are successfully used in other fields of surgery (eg, orthopedics, vascular surgery), where they show favorable long-term biocompatibility. ${ }^{39-41}$ To our knowledge, no reports on Bryan material intolerance have been published. However, patients with allergies should not undergo implantation. Polyurethane is preferred to other polymers used in orthopedics (eg, ultrahigh molecular weight polyethylene [UHMWPE]) because it best emulates the elasticity and shock-absorbing capability of the healthy disc. ${ }^{36}$ Polyurethane has a lower immunologic potential than polyethylene. ${ }^{36}$

Bryan prostheses were exposed to in vitro cyclic fatigue testing. ${ }^{14,39}$ After 10 million cycles, the nucleus mass loss was $1.76 \%$, which is assumed to be $50-100$ times less than that in total hip arthroplasties. ${ }^{39}$ Nucleus height loss was on average $0.02 \mathrm{~mm}$ per million cycles. After 40 million moves, wear averaged $18 \%$ by weight. ${ }^{42}$ Therefore, contact between the shells was imminent. However, in vitro decay is estimated to be significantly higher than in vivo decay (probably 5-10 times). ${ }^{42}$ Under the assumption that 1 million moves occur during 1 year with normal daily activities, the Bryan prosthesis is (optimistically) expected to be functional for more than 40 years. ${ }^{42}$ In animal studies, polymer wear particles had a diameter of $3.9 \mu \mathrm{m}$ on average (most of them in the range of $1-5 \mu \mathrm{m}$ ). ${ }^{8,39}$ There was no debris dissemination into distant organs (lymph node, liver, spleen),${ }^{14}$ penetration of the dura mater, accumulation of metal ion in body fluids, or significant inflammatory response by activation of various cytokines, macrophages, osteoclasts, or other cells..$^{14,42,43}$ In contrast to large joint arthroplasties and metal-on-metal prostheses, Bryan discs obviously do not induce metallic debris formation. ${ }^{8,39,42}$ In a recent study on explanted devices, no case of device fracture, polymer oxidation, or metal corrosion was noted. ${ }^{42}$

Bryan prostheses allow for later MRI and CT examinations. ${ }^{1,4}$ The polyurethane core is not radiopaque. The Bryan prosthesis can be removed if it fails. Normally, the remaining bony endplates allow for conversion to fusion. . $10,18,28,33$

\section{Preoperative measures}

Preoperative measures and surgical procedures have been previously described in detail. ${ }^{3,8,25,44}$

On axial MRI (or CT), the diameters of the caudal and cephalad vertebral endplates adjoining the target disc space 
are assessed. Attention is paid to laying the disc templates on the images that are parallel to the endplates. Bony spurs are excluded from the measurement. The smaller size represents the appropriate prosthesis diameter, and this size will be validated intraoperatively.

General anesthesia is induced, and the patient is positioned supine and exactly adjusted to lie in the middle of the horizontal operating table. The patient's head is slightly elevated and supported (with a donut of $2.5 \mathrm{~cm}$ height). ${ }^{8,36}$ A rolled towel fills the void between the cervical lordosis and the flat table. The head is fixed with tapes, and hence, the cervical spine remains in an accurate neutral position. ${ }^{36}$ The body is firmly strapped to the operating table. In order to minimize superimposition of the shoulder girdle into lateral fluoroscopy images, wide tapes are used to pull the shoulders and arms in the caudal direction (caveat: plexus brachialis). At this point, processus spinosi should be centered between facets in anteroposterior fluoroscopy.

The inclinometer, with a free-swinging, radiopaque pendulum, is taped to the cranial edge of the fluoroscopy apparatus. Using an offprint of the lateral view, the goniometer measures the angle between the pendulum and the line that runs through the superior posterior corner of the cephalad vertebral body and the inferior posterior corner of the caudal vertebral body adjacent to the target disc. This represents the disc space angle, which is eventually used for parallel burring of the endplates and circular precision milling of the recesses (Figure 5).

\section{Bryan surgical procedure}

We prefer an oblique incision along the medial border of the right sternocleidomastoid muscle..$^{22,38,45}$ Alternatively, a curvilinear or transverse incision may be used..$^{23,36,37}$ The platysma muscle is divided, and the main vessels are retracted ipsilaterally using blunt dissection. The trachea together with the oesophagus is displaced contralaterally. Trauma to the longus colli muscles by excessive coagulation or retraction is avoided. The target disc is identified using fluoroscopy. The disc and the hernia are removed, and the lateral parts of the annulus fibrosus and the ligaments remain intact on either side. In contrast to others, ${ }^{11}$ we resect the posterior longitudinal ligament to assure complete decompression. ${ }^{11,12}$ Any anterior, posterior, and foraminal osseous spurs are removed. Then, the $8.5-\mathrm{mm}$ sagittal cam distractor is introduced to evaluate the disc space height and hypermobility or hypomobility of the segment. This examination defines whether arthroplasty or conversion to fusion should be used.

The gravitational referencing system is assembled. ${ }^{3,8,25}$ Sterile extensions are mounted on either side rail of the table.

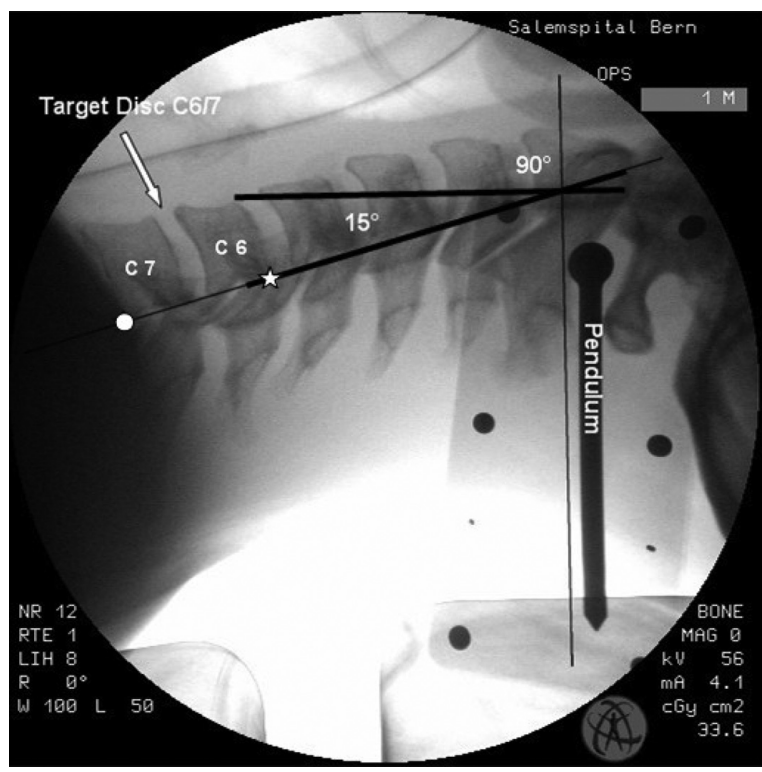

Figure 5 Preoperative lateral fluoroscopy with the patient in definitive position for surgery. The angle between the line that runs through the superior posterior corner (asterix) of the cephalad vertebral body and the inferior posterior corner of the caudal vertebral body (dot) adjacent to the target disc and the pendulum is depicted. In this case, an interspace deviation of $15^{\circ}$ was measured.

A vertical rod is clamped to each extension, and these rods carry the retractor frame. The middle of the frame is centered over the incision (Figure 6). Depending on the patient's trunk anatomy, it is placed a few centimeters above the wound. In this position, the frame is meticulously aligned parallel to the spine and horizontal using a water level. All clamps are firmly closed. Appropriate wound retractor blades are affixed

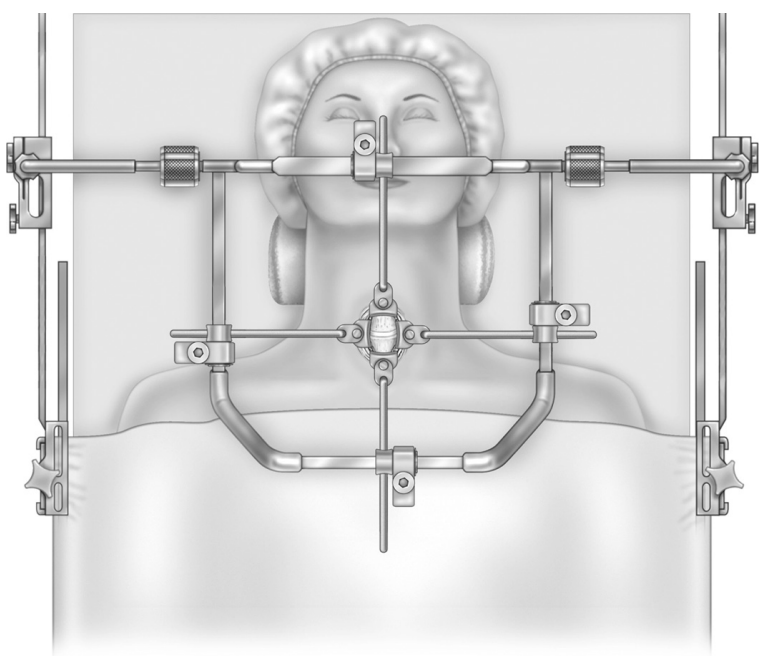

Figure 6 Table extension rails, bilateral vertical rods, Bryan frame, and wound retractors in their definitive positions centered on the exposed intervertebral target disc. Note the rolled towel supporting physiological cervical lordosis. Anesthesia devices are not depicted. Reproduced with permission from Medtronic Sofamor Danek USA, Inc. 
onto either side of the frame. Cephalad and caudal retractions are optional. Exposure is adequate if there is enough space to put the dual-track milling guide on the anterior aspect of the spine. The transverse centering tool marks the sagittal midline. The sagittal wedge is introduced into the space and exactly adjusted to these midline marks. The milling guide is imposed on the wedge. Correct position on the vertebrae is controlled using contact pins and fluoroscopy. The preoperatively assessed sagittal slope of the milling fixture is obtained by using the preset protractor and the water level. In this position, the milling fixture is affixed onto the cranial retractor crossbar and anchored with screws into each adjacent vertebra, and the wedge is removed. Through each guide slot, the milling depth gauge measures the distance between the fixture and the more anterior vertebral edge (Figure 7). The burring block-ring assembly of the assumed prosthesis size is mounted on the fixture. Under fluoroscopic control, the burring depth gauge is lowered through the assembly down to the level of the posterior longitudinal ligament (caveat: injury to the dura) (Figure 7). This returns the burring depth and the definite size of the prosthesis. The calibrated parallel burr is mounted on the assembly. The burr is lowered into the interspace by reducing the assembly height (Figure 8). This feature prevents inadvertent injury of the thecal sac. Bilateral movements of the burr ensure flattening of the whole endplate. After removal of the burr and the assembly, the calibrated milling disc is introduced (Figures 8 and 9). Pivoting movements along the $y$-axis of the spine are applied to create the exact shell geometry in each endplate (Figure 9). Saline is used for irrigation during the motor burring and milling procedures. All instruments but the anchor screws are removed. The anchor post distractor temporarily enlarges the disc space. The introducer instrument, which grasps the device at the holes in the anterior stops, is used to gently hammer the

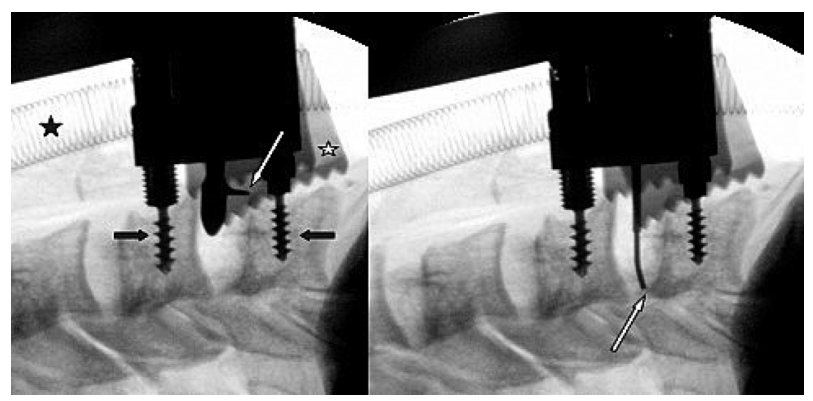

Figure 7 Intraoperative lateral fluoroscopies. Left: milling depth gauge at the anterior edge of the vertebra (white arrow), anchor screws (black arrows), retractor blades (white asterix), and orotracheal anesthesia tube (black asterix). Right: burring depth gauge at the posterior vertebral edge and the remainders of the posterior longitudinal ligament (white arrow).

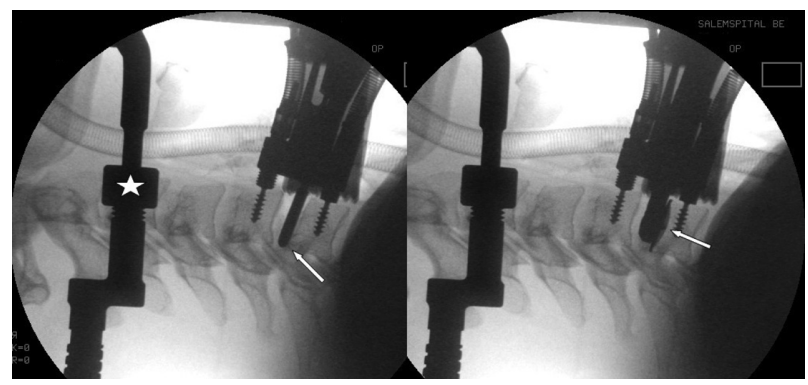

Figure 8 Intraoperative lateral fluoroscopies. Left: close to the thecal sac, the burr abrades the posterior edge (arrow) of the caudal vertebral endplate. Right: the milling disc (arrow) prepares the recess. Note the screw-anchored fixture, lateral retractors, vertical bar (asterix), and the orotracheal anesthesia tube.

prepared device into the space. Lateral and anteroposterior fluoroscopy controls the correct device position. After the removal of the anchors, the wound is thoroughly rinsed ${ }^{32}$ in order to eliminate bone dust and sutured over a closed suction drain. Although blood loss is negligible in general (64 mL, ${ }^{9} 80$

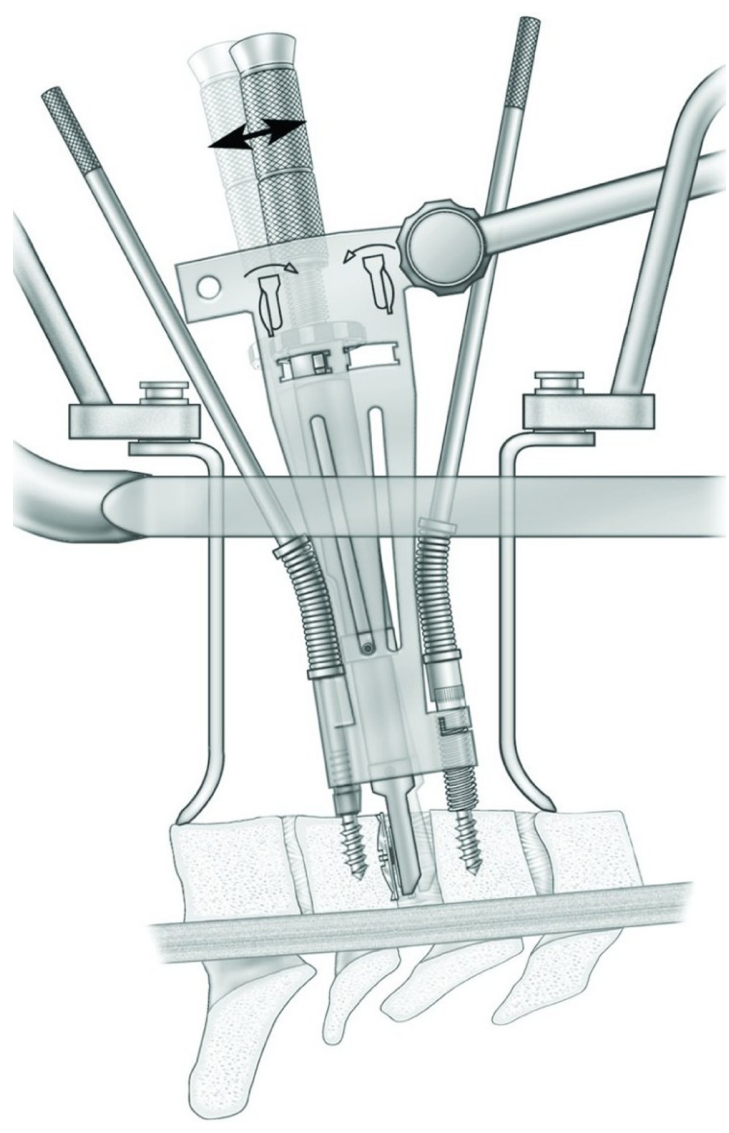

Figure 9 Pivoting moves (double arrow) are applied to the milling disc during preparation of the vertebral recess. Note the thecal sac containing the myelon next to the posterior rim of the milling disc. The hook in the slit of the fixture avoids inadvertent neural element lesion. The milling fixture is affixed to the anterior aspect of the spine. Two anchor screws and extensions to the cranial crossbar secure its position in the previously determined angle. Optional cranial and caudal wound retractors are mounted. A longitudinal bar of the frame is depicted. Reproduced with permission from Medtronic Sofamor Danek USA, Inc. 
$\mathrm{mL}[42 \mathrm{~mL}$ for ACDF $],{ }^{24} 90 \mathrm{~mL}[50-130 \mathrm{~mL}],{ }^{4} 97.5 \pm 77.6$ $\mathrm{mL}$ [maximum 300], $208 \mathrm{~mL}^{11}$ ), blood transfusions ${ }^{37}$ may be indicated in exceptional cases.

The above procedure describes the single-level method. ${ }^{3,8,25}$ For bi-level procedures, several instruments are exchanged and repositioned. The surgical exposure is more extensive; otherwise, there are no major procedural changes. The complexity and learning curve ${ }^{44,46}$ of the actual Bryan system have the potential to repel some surgeons. A simplified implantation procedure using the identical prosthesis is currently under development.

We do not perform this procedure on an outpatient basis. Our patients remain in the recovery room overnight in order to cover the first of the critical 36 hours after surgery. ${ }^{47} \mathrm{Hema}-$ tomas may rarely compress the trachea or the thecal sac in a dramatic manner early after surgery., 31,47

In contrast to ACDF, no collars are used in this procedure. ${ }^{1,3,14}$ The patients ambulate within a few hours. They are allowed to resume nonstrenuous activities immediately ${ }^{18}$ and usually return to work earlier than ACDF patients. ${ }^{11,18,23}$ Thus, the overall costs are reduced to some extent.

\section{Complications of the Bryan disc prosthesis and their prevention}

Complications occur at various stages. ${ }^{28}$ They are related to the surgical access, the Bryan system procedure, and the long-term behavior of the device. Complications depend on the number of implants. ${ }^{25,28,47}$ Goffin et $\mathrm{al}^{25}$ reported a complication rate of $6.8 \%$ for single-level procedures, $11.6 \%$ for bi-levels, and an overall complication rate of $6.3 \%$ per treated level. Pickett et al ${ }^{28}$ reported $8.1 \%$ perioperative complications, equivalent to $6.2 \%$ per treated level. They also reported $5.2 \%$ of late-onset complications at the mean follow-up of 12 months.

Most surgeons switch from ACDFs involving anterior approaches to Bryan procedures. Therefore, there is no major learning curve for the identical Bryan approach. Vital structures such as the internal carotid artery, the superior thyroid artery, the internal jugular vein, the trachea, the esophagus ${ }^{25}$ and the thecal sac containing neural elements are seldom injured. Aggravation of preexisting neurological dysfunction is rare. ${ }^{28}$ However, undetected retraction and compression trauma to adjoining structures is a concern. ${ }^{25}$ Thus, anterior approaches are associated with temporary dysphagia (incidence of $\left.12.3 \%^{48}\right)$, dysphonia $\left(7 \%^{4}\right)$, hoarseness $\left(4.9 \%{ }^{48}\right)$, and unilateral, true vocal cord paresis $\left(1.4 \%{ }^{48}\right)$. Hidden bleeding points inadvertently created by transection of small vessels may lead to the formation of life-threatening prevertebral or epidural hematoma shortly after the surgery. ${ }^{10,11,28,33}$ Horner syndrome, venous air embolism, and chylothorax formation have not been reported.

Postoperative kyphosis through the Bryan device and/or the treated functional spinal unit is increasingly reported. ${ }^{11,12,33,36,44}$ The complexity of the Bryan procedure, which is associated with a substantial learning curve, and the inclusion of patients with preexisting malalignment may contribute to its incidence. ${ }^{44}$ Kyphosis formation can sometimes be prevented by a slight modification of the milling guide angle, avoidance of asymmetric endplate preparation, endplate overmilling, and compression of the prosthesis during closure of the second seal plug. . $^{11,12,34-36,44,49}$ Robertson et $\mathrm{l}^{10}$ studied preoperative kyphosis in some patients: 12 with slight, 11 with mild, and 12 with severe preoperative kyphosis. Slight kyphosis turned into normal lordosis in six patients, remained unchanged in four, and worsened to severe in two. Mild kyphosis diminished to slight in four patients, remained unchanged in four, and became severe in three. Severe kyphosis remained severe in all instances. Postoperative severe kyphosis decreased prosthesis motion. Fong et $\mathrm{al}^{36}$ reported that 9 of 10 patients had kyphosis through the prosthesis at a mean follow-up of 4 months (3-12 months). Pickett et $\mathrm{al}^{49}$ observed kyphosis formation in all of their 14 patients. Their prostheses moved, and the overall cervical alignment was preserved (follow-up, 6-24 months; mean, 12 months). Kyphosis most frequently remains asymptomatic. ${ }^{11}$

Both myositis ossificans and heterotopic ossification contribute to fusion of the prosthesis. Myositis ossificans is induced by the excessive coagulation and retraction damage of the longus colli muscles..$^{12,32,50}$ Mesenchymal cells released from muscle components may transform into ossification-inducing cells. Heterotopic ossification occurs in approximately $6 \%-12 \%$ of cases $^{4,25,28,32,33,38,51,52}$ and progresses from hardly detectable bony spurs to solid fusion. A grading system (Class 0 [no ossification] to 4 [ossification causing inadvertent arthrodesis]) was introduced for lumbar arthroplasty. ${ }^{53}$ Endplate burring and milling release bone dust that contains osteogenic precursor cells, bone morphogenic protein, and various cytokines. ${ }^{12,32,43,53,54}$ Copious rinsing of the wound and use of nonsteroidal anti-inflammatory drugs (NSAIDs) in the early postoperative period ( $2-4$ weeks) is supposed to act against ossification. ${ }^{12,14,18,28,32,52}$ However, there remains some concern that NSAIDs compromise bony shell ingrowth ${ }^{32}$ as well. Solid fusion turns the device into a nonmoving disc space filler, which behaves very much like a primary ACDF. ${ }^{4,28,32,51}$ However, the protective effect 
on adjacent segments is lost. ${ }^{32}$ Unless radiological controls are performed, spontaneous prosthesis fusion may remain undiscovered. No treatment is required as long as fusion is asymptomatic.

It is mandatory to implant the largest prosthesis possible. ${ }^{38}$ Huge shells cover most of the vertebral surface from which bridging syndesmophytes might originate. Large spheres also distribute strain over large areas of the device. Longevity of the device is optimized, the probability of subsidence is minimized, and the area of bony ingrowth is maximized.

Prior to system adaptation, prosthesis dislocation in the $\mathrm{z}$-axis occurred due to milling mistakes, ${ }^{25}$ but now, anteroposterior prosthesis dislocation is rare. Inferior plate dislocation of the device requiring removal of the prosthesis with conversion to fusion has been described. ${ }^{4,28}$ Internal subluxation of the device occurred in a case of segmental hypermobility. ${ }^{37}$

There is no report of cervical prosthesis infection, prosthesis subsidence, or aseptic osteolysis due to wear debris formation. Little is known about same-segment disease involving facet arthrosis and the recurrence of uncoforaminal bony spurs. ${ }^{55}$ In case of bi-level treatment, prosthesis spheres may even contact each other. ${ }^{28}$ Wrong-level surgery should be an exception. ${ }^{3,10,25}$

\section{Outcome}

Late outcome of neural element decompression is expected to be the same for both ACDF and Bryan procedures. ${ }^{14}$ However, published outcomes at more than 5 years are not available for Bryan arthroplasty. ${ }^{33}$ The following is not a complete review of the literature, and the patients and the results in some studies may overlap.

Bryan ${ }^{14}$ presented the first 97 patients who received single-level prosthesis implantation in several European centers. Using modified Odom's ${ }^{56}$ criteria, clinical success was reported to be $87 \%(n=40)$ after 1 year and $89 \%(n=8)$ after 2 years. At 1 year, in $86 \%$ (38 of 44 ) of patients, the flexion-to-extension angle was $8^{\circ} \pm 5^{\circ}$ on average, and in 4 patients, it was $1^{\circ}$. At 2 years, $100 \%$ (10 of 10) of prostheses moved $\left(11^{\circ} \pm 5^{\circ}\right)$. High patient satisfaction was noted, and there were no restrictions on the activities of daily living. One patient had evacuation of a wound hematoma, and another had foraminotomy to remove a remaining osteophyte. In one patient, the device migrated over $2 \mathrm{~mm}$ in the anteroposterior direction; otherwise, there were no prosthesis dislocations, subsidences, failures, bridging, or inflammatory response to the prosthesis.
Goffin et $\mathrm{al}^{3}$ conducted a prospective, concurrently enrolled, European multicenter trial on 60 patients with single-level prosthesis. Using modified Odom's criteria, clinical success was obtained in $86 \%$ (52 of 60) of patients at 6 months and in 90\% (27 of 30) of patients at 1 year. At 12 months, patients met or exceeded the US population mean for SF-36 physical and mental component scores. ${ }^{57}$ At 6 months, flexion-to-extension angles were just less than $9^{\circ} \pm 4^{\circ}$ in $93 \%$ (53 of 57) of patients. At 1 year, they were just more than $9^{\circ} \pm 6^{\circ}$ in $88 \%$ (21 of 24 ) of patients, and two had fused segments $\left(1^{\circ}\right)$. Anteroposterior migration ( $\leq 3 \mathrm{~mm}$ ) was observed in one patient and suspected in another. There was no device failure, subsidence, bridging, or explantation. Two patients had anterior or posterior revision surgery for additional neural element decompression. One had shortness of breath, requiring hematoma evacuation, and one wrong level was operated.

Goffin et $\mathrm{al}^{25}$ again reported on the European multicenter study. Single-level Bryan arthroplasty $(n=103)$ was a clinical success (excellent, good, fair) in 90\% (83 of 92), 86\% (76 of 89 ), and $90 \%$ (44 of 49) of patients after 6,12 , and 24 months, respectively. In bi-level Bryan arthroplasty $(n=43)$, clinical success was $82 \%$ after 6 months and $96 \%$ after 12 months. After 1 year, $88 \%$ of single-level and $86 \%$ of bi-level Bryan prostheses moved. After 2 years, $93 \%$ of single-level Bryan prostheses moved $>2^{\circ}$. Flexion-to-extension angles were $7.9^{\circ} \pm 5.3^{\circ}$ for single-level prostheses, and $7.4^{\circ} \pm 5.1^{\circ}$ for bi-level prostheses at 1-year follow-up.

Leung et $\mathrm{al}^{32}$ reviewed 90 patients at 12-month followups. The incidence of heterotopic ossification was 17.8\% (16 of 90 patients). Among them, 6.7\% $(n=6)$ of patients had Class 3 or 4 ossification $^{53}$ and another $11 \%(n=10)$ had a range of motion of $<2^{\circ}$. Nevertheless, $89.9 \%$ ( 80 of 89 ) of patients had a favorable Odom's outcome at 1 year so that there was no association between ossification and clinical outcome.

Lafuente et $\mathrm{al}^{4}$ conducted an observational clinical study involving 46 patients with single-level Bryan prostheses. Visual analog scale (VAS), ${ }^{58}$ SF-36 physical component, SF-36 mental component, and neck disability index (NDI) ${ }^{59}$ improved in a statistically significant manner in all patients. Odom's criteria were satisfactory in $84 \%$ and $89 \%$ patients at 1 -year and 2 -year follow-ups, respectively. The range of motion was $7.72^{\circ}$ on average (range, $\left.0^{\circ}-17^{\circ}\right)$. Two patients $(4.3 \%$ ) had ankylosis and a good clinical outcome. In one patient, the prosthesis was removed, and the segment was fused because of interior 
disc plate dislodgment. There was no subsidence. Interestingly, they operated on a patient who had quadraparesis due to disc herniation, patients with previous spine surgery, and those with other-level fusions.

Sekhon et $\mathrm{a}^{37}$ reported on a prospective study involving 15 patients receiving 24 devices (1-3 levels). All had previously undergone anterior or posterior cervical spine surgery. Follow-up was $24.2 \pm 10.5$ months. VAS was $7.8 \pm 3.3$ preoperatively and $1.4 \pm 2.6$ postoperatively. The Oswestry $^{60}$ disability index was $27.1 \pm 15.6$ before and $17.6 \pm 8.5$ after surgery. Range of motion was $5.5^{\circ} \pm 4.7^{\circ}$ before and $4.3^{\circ} \pm 2.6^{\circ}$ after surgery. No revision surgery was required; however, one patient experienced hypermobility with internal subluxation of the device, and two required blood transfusions. Interestingly, one patient had clicking of the prosthesis.

Pickett et a ${ }^{28}$ assessed 74 patients with 96 Bryan prostheses, who were followed for a mean of 12 months (maximum 36 months). NDI changed from $20.1 \pm 9.2$ preoperatively to $7.1 \pm 9.6$ postoperatively; the Oswestry disability index from $34.4 \pm 8.7$ to $17.0 \pm 9.7$; VAS from $6.9 \pm 3.0$ to $1.7 \pm 2.2$; SF-36 physical component from $34.3 \pm 10.5$ to $46.5 \pm 9.1$ and mental component from $44.1 \pm 10.3$ to $50.3 \pm 7.9$. Two prostheses fused (heterotopic ossification; undersized prosthesis) and 92 moved $8.13^{\circ}$ on average. Neck pain was present in 19 patients (25\%). There was one Bryan failure, probably due to internal subluxation of the nucleus in extension, and one late-onset migration of the device inducing regional kyphosis. Three patients required further decompressions, and one required exchange of the prosthesis because of kyphosis formation. One retropharyngeal hematoma was evacuated.

Yoon et a ${ }^{11}$ retrospectively studied 46 single-level Bryan patients at 11.8 (2.9-19.5) months after surgery. Twelve of them received a combination of prosthesis and single-level fusion. NDI changed from $74 \%$ preoperatively to $24 \%$ at 1 year, radiating pain VAS changed from 8.15 to 1.35 , and neck pain VAS changed from 6.5 to 3.8. However, in four patients, neck pain VAS increased from 5.32 to 6.9 and NDI increased from $67 \%$ to $75 \%$ at 13.8 months on average. The range of motion of the treated segment was $13.3^{\circ} \pm 5.7^{\circ}$ before surgery, $9.3^{\circ} \pm 3.7^{\circ}$ at 1 month after surgery, and recovered to $14.4^{\circ} \pm 4.5^{\circ}$ at 1 year. Using conservative therapy, a patient fully recovered from quadriplegia due to an acute subdural hematoma. There was no fusion or device migration.

Sasso et $\mathrm{al}^{9}$ presented a prospective, randomized trial. In the Bryan arm, there were 56 patients treated at one level.
With statistical significance, all outcome scores improved from the preoperative period to the postoperative period. NDI changed from 47 preoperatively to 11 at 2 years $(n=49)$, arm pain VAS from 70 to 14 , neck pain VAS from 72 to 16 , SF-36 physical component score from 34 to 51, and SF-36 mental component from 46 to 54. Flexion-to-extension angle was $7.9^{\circ}$ on average at 2 years. There were no fusions, device failures, explantations, or intraoperative complications. Later, two patients required further surgery for adjacent-segment disease.

Heidecke et $\mathrm{al}^{33}$ published a prospective study of 54 patients receiving 59 Bryan prostheses. All patients had either good or excellent outcomes (Odom) at 2 years, and moving protheses had a $6^{\circ} \pm 3^{\circ}$ range of motion. No useful motion $\left(<3^{\circ}\right)$ was observed in seven single-level patients $(12 \%)$. Among them, five had heterotopic ossification Class 3 or 4, and two had none. In the remaining cohort, ossification Class 1 or 2 was present in 12 segments (overall 17 segments or $29 \%$ ). One retropharyngeal hematoma was evacuated, and one dysfunctional prosthesis had to be removed and was converted to fusion. Migrations or dislocations did not occur.

Riew et $\mathrm{al}^{5}$ performed a cross-sectional analysis of two prospective, randomized multicenter trials to evaluate arthroplasty in myelopathy patients. In the Bryan trial, there were 47 arthroplasty patients. NDI, neck pain VAS, arm pain VAS, SF-36 physical component, and SF-36 mental component improved in a statistically significant manner. At 2 years, $89.7 \%$ of patients had improvement or maintenance of neurological status, $46.2 \%$ had improvement in gait function, nobody had deterioration of gait function, and $94.7 \%$ were satisfied with the outcome. There was no revision surgery and no implant-related adverse events.

Cheng et $\mathrm{al}^{23}$ carried out a prospective, controlled, randomized clinical trial. In the two-level Bryan arm $(n=31)$, neck pain VAS changed from 7.3 preoperatively to 1.5 at 2 years, arm pain VAS from 7.1 to 1.4 , NDI from 50 to 11 , and SF-36 physical component score from 35 to 50 . Odom's scale was excellent, good, or fair for all. Range of motion was $7.9^{\circ}$ on average at 2 years. Apart from a deep-vein thrombosis, there were no complications in the Bryan cohort.

Yang et al ${ }^{12}$ studied 15 single-level Bryan arthroplasty patients for 29.5 months on average (24-35 months). For all patients Odom's criteria were excellent, good, or fair at 2 years. With statistic significance, the VAS changed from 7.0 before surgery to 2.4 at 2 years, NDI from 23.0 to 8.9 , and the Bryan range of motion was $10.4 \pm 2.7^{\circ}$ before surgery 
and $10.9 \pm 2^{\circ}$ at 2 years. Interestingly, the range of motion decreased 1 month postoperatively (as seen in other studies), but recovered later.

Heller et $\mathrm{al}^{18}$ reported on a randomized, controlled, multicenter clinical trial. In the Bryan arm, 242 patients underwent single-level treatment. Mean NDI improved from 51.4 preoperatively to 16.2 at 2 years, arm pain VAS score from 71.2 to 19.1, neck pain VAS score from 75.4 to 23 , SF-36 physical component from 32.6 to 47.9 , SF-36 mental component from 42.3 to 51.7 , and the range of motion from $6.5^{\circ} \pm 3.4^{\circ}$ to $8.1^{\circ} \pm 4.8^{\circ}$. Improvements were statistically significant. Overall success rate was $82.6 \%$ (17.4\% failure); $1.7 \%$ of patients experienced implant-related adverse events, and $2.5 \%$ had secondary surgical procedures at the treated level (one revision, three removals, and two reoperations). Range of motion slightly increased during follow-up. There was no fusion, and the Bryan patients returned to work earlier.

Garrido et $\mathrm{al}^{24}$ undertook a prospective, randomized, controlled trial. In the Bryan arm, there were 18 patients available for a 48-month follow-up. All had single-level treatment. Their NDI improved from 51 preoperatively to 10 at 4 years, neck pain VAS from 76.2 to 13.6 , arm pain VAS from 78.8 to 10.8 , SF-36 physical component from 33.1 to 49.4 , and SF-36 mental component from 43.2 to 53.5. Overall results were more favorable for the Bryan than the ACDF cohort. Revision surgeries were more frequent in the ACDF group $(n=6 ; 23 \%)$. One patient $(5 \%)$ of the Bryan group had a follow-up surgery for adjacent-segment disease. They conclude that arthroplasty may progressively replace $\mathrm{ACDF}$.

$\mathrm{We}^{38}$ retrospectively followed 25 patients with 29 prostheses for $22.3 \pm 9.4$ months (range, 11.5-45.6). One prosthesis fused, and the remaining 28 moved $9.5^{\circ} \pm 4.7^{\circ}$ on average (range, $3^{\circ}-20^{\circ}$ ) (Figure 10). This range of motion was very similar to that of adjacent untreated segments. There

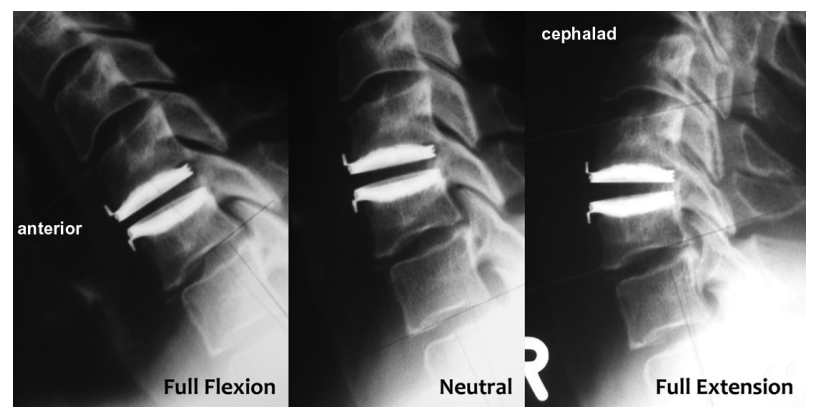

Figure 10 Functional lateral radiographs, 3 months after successful Bryan arthroplasty (diameter, $17 \mathrm{~mm}$ ) for C5/6 disc herniation in a 49-year-old woman. The prosthesis moves physiologically. There is a minimal area of failed (or delayed) bone ingrowth at the posterior border of the upper shell. was no reoperation, device-related complications, prosthesis dislocation, or subsidence. For unknown reasons, the fused prosthesis had been implanted eccentrically. Although it was not stated in our article, several patients temporarily complained about postoperative dysphagia or neck pain. No patient was treated for myelopathy.

\section{Conclusions}

Total disc arthroplasty in the cervical spine is associated with important advantages. Bryan prostheses challenge the goldstandard ACDF in the treatment of cervical degenerative discopathy associated with eventual neural impingement. Neural structures are reliably decompressed. Prostheses maintain physiological alignment, kinematics, and biomechanics of the segment. In this way, accelerated transient-segment degeneration with subsequent radiculomyelopathy is averted with high probability. Patient's satisfaction, safety, tolerability, and longevity of the Bryan prosthesis system seem to be very acceptable. Bone graft harvest site morbidity is eliminated. Frequently, patients return to work earlier.

However, Bryan prostheses have the disadvantage of high implant costs, technical complexity of the implantation procedure, implant-associated complications, and spontaneous fusion.

At present, the lack of long-term results of more than 5 years obviates a more definite appreciation. As a consequence, the definite role of the Bryan device in the therapy of degenerative discopathy and disc herniation is not yet settled.

\section{Acknowledgments and disclosures}

The authors have no commercial interest in the Bryan system. No funds were or will be received for this review. Figures 1-4, 6, and 9 were provided by Medtronic Sofamor Danek USA, Inc., with permission (the Bryan ${ }^{\circledR}$ Cervical Disc System incorporates technology developed by Gary $\mathrm{K}$ Michelson, MD).

\section{References}

1. Durbhakula MM, Ghiselli G. Cervical total disc replacement, part I: rationale, biomechanics, and implant types. Orthop Clin North Am. 2005;36(3):349-354.

2. Hilibrand AS, Carlson GD, Palumbo MA, Jones PK, Bohlman HH. Radiculopathy and myelopathy at segments adjacent to the site of a previous anterior cervical arthrodesis. J Bone Joint Surg Am. 1999;81$\mathrm{A}(4): 519-528$.

3. Goffin J, Casey A, Kehr P, et al. Preliminary clinical experience with the Bryan cervical disc prosthesis. Neurosurgery. 2002;51(3):840-847.

4. Lafuente J, Casey ATH, Petzold A, Brew S. The Bryan cervical disc prosthesis as an alternative to arthrodesis in the treatment of cervical spondylosis. 46 consecutive cases. J Bone Joint Surg Br. 2005;87(4):508-512. 
5. Riew KD, Buchowski JM, Sasso R, Zdeblick T, Metcalf NH, Anderson PA. Cervical disc arthroplasty compared with arthrodesis for the treatment of myelopathy. J Bone Joint Surg Am. 2008;90(11):2354-2364.

6. Wigfield C, Gill S, Nelson R, Langdon I, Metcalf N, Robertson J. Influence of an artificial cervical joint compared with fusion on adjacentlevel motion in the treatment of degenerative cervical disc disease. J Neurosurg. 2002;96 Suppl 1:17-21.

7. Matsunaga S, Kabayama S, Yamamoto T, Yone K, Sakou T, Nakanishi K. Strain on intervertebral discs after anterior cervical decompression and fusion. Spine. 1999;24(7):670-675.

8. Wang MY, Leung CH, Casey AT. Cervical arthroplasty with the Bryan disc. Neurosurgery. 2005;56 Suppl 1:58-65.

9. Sasso RC, Smucker JD, Hacker RJ, Heller JG. Artificial disc versus fusion. A prospective, randomized study with 1-year follow-up on 99 patients. Spine. 2007;32(26):2933-2940.

10. Robertson JT, Papadopoulos SM, Traynelis VC. Assessment of adjacentsegment disease in patients treated with cervical fusion or arthroplasty: a prospective 2-year study. J Neurosurg Spine. 2005;3(12):417-423.

11. Yoon DH, Yi S, Shin HC, Kim KN, Kim SH. Clinical and radiological results following cervical arthroplasty. Acta Neurochir. 2006;148(9): 943-950.

12. Yang YC, Nie L, Cheng L, Hou Y. Clinical and radiographic reports following cervical arthroplasty: a 24-month follow-up. Int Orthop. 2009;33(4):1037-1042.

13. Traynelis VC. Cervical arthroplasty. Clin Neurosurg. 2006;53: 203-207.

14. Bryan VE Jr. Cervical motion segment replacement. Eur Spine J. 2002;11 Supp1 2:S92-S97.

15. Auerbach JD, Jones KJ, Fras CI, Balderston JR, Rushton SA, Chin KR The prevalence of indications and contraindications to cervical total disc replacement. Spine J. 2008;8(5):711-716.

16. Smith GW, Robinson RA. The treatment of certain cervical-spine disorders by anterior removal of the intervertebral disc and interbody fusion. J Bone Joint Surg Am. 1958;40A(3):607-624.

17. Cloward RB. The anterior approach for removal of ruptured cervical disks. J Neurosurg. 1958;15(6):602-617.

18. Heller JG, Sasso RC, Papadopoulos SM, et al. Comparison of Bryan cervical disc arthroplasty with anterior cervical decompression and fusion. Clinical and radiographic results of a randomized, controlled, clinical trial. Spine. 2009;34(2):101-107.

19. Cloward RB. The treatment of ruptured intervertebral discs by vertebral body fusion. Ann Surg. 1952;136(6):987-992.

20. Bailey RW, Badgley CE. Stabilization of the cervical spine by anterior fusion. J Bone Joint Surg Am. 1960;42A:565-594.

21. Hacker RJ, Cauthen JC, Gilbert TJ, Griffith SL. A prospective randomized multicenter clinical evaluation of an anterior cervical fusion cage. Spine. 2000;25(20):2646-2654.

22. Wenger M. Monosegmental, degenerative, cervical discopathy treated by surgery with insertion of an intervertebral cage. Review [in French]. Rev Med Suisse Romande. 2002;122(7):351-353.

23. Cheng L, Nie L, Zhang L, Hou Y. Fusion versus Bryan cervical disc in two-level cervical disc disease: a prospective, randomised study. Int Orthop. 2009;33(5):1347-1351.

24. Garrido BJ, Taha TA, Sasso RC. Clinical outcomes of Bryan cervical disc arthroplasty. A prospective, randomized, controlled, single site trial with 48-month follow-up. J Spinal Disord Tech. Epub 2010 Jan 16.

25. Goffin J, van Calenbergh F, van Loon J, et al. Intermediate follow-up after treatment of degenerative disc disease with the Bryan cervical disc prosthesis: single-level and bi-level. Spine. 2003;28(24):2673-2678.

26. Eck JC, Humphreys SC, Lim TH, et al. Biomechanical study on the effect of cervical spine fusion on adjacent-level intradiscal pressure and segmental motion. Spine. 2002;27(22):2431-2434.

27. Goffin J, Geusens E, Vantomme N, et al. Long-term follow-up after interbody fusion of the cervical spine. J Spinal Disord Tech. 2004; 17(2):79-85.
28. Pickett GE, Sekhon LHS, Sears WR, Duggal N. Complications with cervical arthroplasty. J Neurosurg Spine. 2006;4(2):98-105.

29. Sandhu HS, Grewal HS, Parvataneni H. Bone grafting for spinal fusion. Orthop Clin North Am. 1999;30(4):685-698.

30. Silber JS, Anderson DG, Daffner SD, et al. Donor site morbidity after anterior iliac crest bone harvest for single-level anterior cervical discectomy and fusion. Spine. 2003;28(2):134-139.

31. Modic MT, Steinberg PM, Ross JS, Masaryk TJ, Carter JR. Degenerative disk disease: assessment of changes in vertebral body marrow with MR imaging. Radiology. 1988;166(1 Pt 1):193-199.

32. Leung C, Casey AT, Goffin J, et al. Clinical significance of heterotopic ossification in cervical disc replacement: a prospective multicenter clinical trial. Neurosurgery. 2005;57(4):759-762.

33. Heidecke V, Burkert W, Brucke M, Rainov NG. Intervertebral disc replacement for cervical degenerative disease - clinical results and functional outcome at two years in patients implanted with the Bryan cervical disc prosthesis. Acta Neurochir. 2008;150(5):453-459.

34. Goffin J. Comment. Acta Neurochir. 2006;148(9):950.

35. Goffin J. Comment. Acta Neurochir. 2008;150(5):459.

36. Fong SY, DuPlessis SJ, Casha S, Hurlbert RJ. Design limitations of Bryan disc arthroplasty. Spine J. 2006;6(3):233-241.

37. Sekhon LH, Sears W, Duggal N. Cervical arthroplasty after previous surgery: results of treating 24 discs in 15 patients. J Neurosurg Spine. 2005;3(5):335-341.

38. Wenger M, van Hoonacker P, Zachee B, Lange R, Markwalder TM. Bryan cervical disc prostheses: preservation of function over time. J Clin Neurosci. 2009;16(2):220-225.

39. Anderson PA, Rouleau JP, Bryan VE, Carlson CS. Wear analysis of the Bryan cervical disc prosthesis. Spine. 2003;28 Suppl 20:S186-S194.

40. Tiwari A, Salacinski H, Seifalian AM, Hamilton G. New prostheses for use in bypass grafts with special emphasis on polyurethanes. Cardiovasc Surg. 2002;10(3):191-197.

41. Bernacca GM, Mackay TG, Gulbransen MJ, Donn AW, Wheatley DJ. Polyurethane heart valve durability: effects of leaflet thickness and material. Int J Artif Organs. 1997;20(6):327-331.

42. Anderson PA, Rouleau JP, Toth JM, Riew KD. A comparison of simulator-tested and -retrieved cervical disc prostheses. Invited submission from the Joint Section Meeting on Disorders of the Spine and Peripheral Nerves, March 2004. J Neurosurg Spine. 2004;1(2):202-210.

43. Goodman SB, Huie P, Song Y, et al. Cellular profile and cytokine production at prosthetic interfaces. Study of tissues retrieved from revised hip and knee replacements. J Bone Joint Surg Br. 1998;80(3):531-539.

44. Shim CS, Lee SH, Park HJ, Kang HS, Hwang JH. Early clinical and radiologic outcomes of cervical arthroplasty with Bryan cervical disc prosthesis. J Spinal Disord Tech. 2006;19(7):465-470.

45. Wenger M, Adam PJ, Alarcón F, Markwalder TM. Traumatic cervical instability associated with cord oedema and temporary quadriparesis. Spinal Cord. 2003;41(9):521-526.

46. Lee MC, Kim DH. Comment. Neurosurgery. 2005;56 Suppl 1:65.

47. Sagi HC, Beutler W, Carroll E, Connolly PJ. Airway complications associated with surgery on the anterior cervical spine. Spine. 2002;27(9):949-953.

48. Baron EM, Soliman AM, Gaughan JP, Simpson L, Young WF. Dysphagia, hoarseness, and unilateral true vocal fold motion impairment following anterior cervical diskectomy and fusion. Ann Otol Rhinol Laryngol. 2003;112(11):921-926.

49. Pickett GE, Mitsis DK, Sekhon LH, Sears WR, Duggal N. Effects of a cervical disc prosthesis on segmental and cervical spine alignment. Neurosurg Focus. 2004;17(3):E5.

50. Ahrengart L, Sahlin K, Lindgren U. Myositis ossificans after total hip replacement and perioperative muscle ischemia. $J$ Arthroplasty. 1987;2(1):65-69.

51. Bartels RH, Donk R. Fusion around cervical disc prosthesis: case report. Neurosurgery. 2005;57(1):E194.

52. Parkinson JF, Sekhon LHS. Cervical arthroplasty complicated by delayed spontaneous fusion. J Neurosurg Spine. 2005;2(3):377-380. 
53. McAfee PC, Cunningham BW, Devine J, Williams E, Yu-Yahiro J. Classification of heterotopic ossification $(\mathrm{HO})$ in artificial disk replacement. J Spinal Disord Tech. 2003;16(4):384-389.

54. Puzas JE, Miller MD, Rosier RN. Pathologic bone formation. Clin Orthop Relat Res. 1989;245:269-281.

55. McCormick P. Comment. Neurosurgery. 2005;57(4):763.

56. Odom GL, Finney W, Woodhall B. Cervical disk lesions. J Am Med Assoc. 1958;166(1):23-28.

57. Garratt AM, Ruta DA, Abdalla MI, Buckingham JK, Russell IT. The SF36 health survey questionnaire: an outcome measure suitable for routine use within the NHS? BMJ. 1993;306(6890):1440-1444.
58. Huskisson EC. Measurement of pain. Lancet. 1974;2(7889): 1127-1131.

59. Vernon H, Mior S. The neck disability index: a study of reliability and validity. J Manipulative Physiol Ther. 1991;14(7):409-415.

60. Fairbank J, Pynsent P. The Oswestry disablility index. Spine. 2000;25(22):2490-2452.

\section{Publish your work in this journal}

Medical Devices: Evidence and Research is an international, peerreviewed, open access journal that focuses on the evidence, technology, research, and expert opinion supporting the use and application of medical devices in the diagnosis, treatment and management of clinical conditions and physiological processes. The identification of novel devices and optimal use of existing devices which will lead to improved clinical outcomes and more effective patient management and safety is a key feature. The manuscript management system is completely online and includes a quick and fair peer-review system. Visit http://www. dovepress.com/testimonials.php to read real quotes from authors.

Submit your manuscript here: http://www.dovepress.com/medical-devices-evidence-and-research-journal 